\title{
Farewell to Professor Dr. Jolán Bánóczy
}

On Wednesday, the 31st of August, 2016, we lost Professor Jolán Bánóczy, who died at the age of 88 years.

Professor Jolán Bánóczy graduated with an MD at the Semmelweis University in Budapest, Hungary, in 1953. She received her DMD diploma in 1956, defended her $\mathrm{PhD}$ thesis "Keratinization of the Oral Mucosa in Physiological and Pathological Circumstances" in 1968, and received her DSc degree in 1978 with the thesis "Clinicopathological Significance of Oral Leukoplakia”.

Her scientific activity may be grouped into three periods. In the first period, during more than 25 years, she investigated oral precancerous lesions, together with a WHO group led by Professor Pindborg. Her follow-up studies on 670 cases of oral leukoplakia, controlled over 30 years, represent the most extensive material and the longest period of follow-up in this field. She determined the clinical, histological, and ultrastructural characteristics of the risk groups of oral leukoplakias. Her book Oral Leukoplakia was published in English in 1982 and in Japanese in 1986, and about 80 scientific papers, some of which appeared in international journals, were also produced in this period.

The second scientific field of Jolán Bánóczy, beginning in the 1970s, and continuing for the next 30 years, consisted of her investigations into the etiology and prevention of dental caries. In this respect, in a WHO and Finnish collaboration, she investigated the caries-reducing effect of polyol-containing sweets. The results of these Hungarian xylitol studies were published in Acta Odontologica Scandinavica in 1985, and also in numerous papers that reported on clinical, epidemiological, and microbiological changes as well as on the structural changes

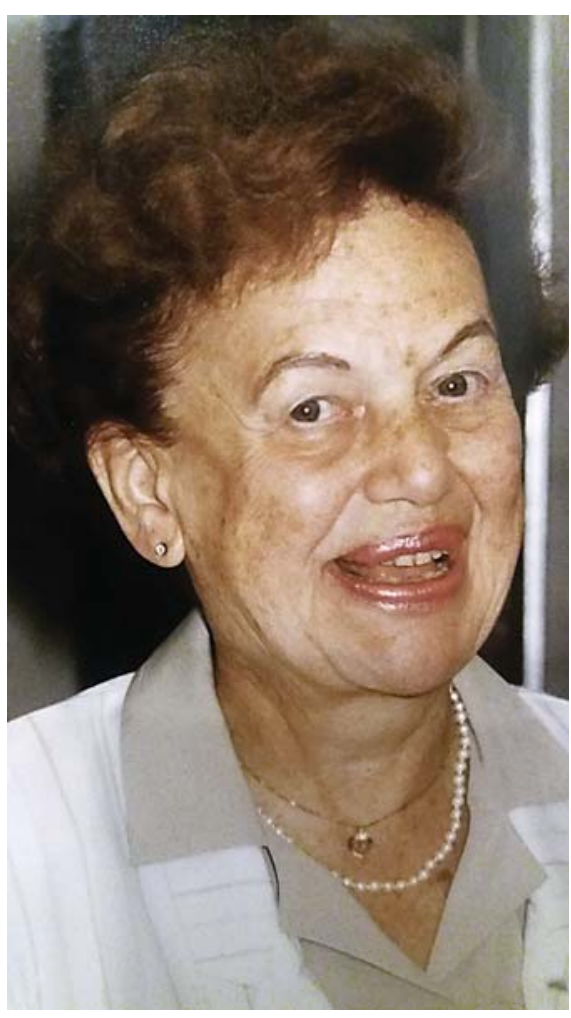

Professor Dr. Jolán Bánóczy

in dental enamel. Follow-up studies after 5 and 10 years, on the consumption of fluoridated milk, brought a considerable reduction in caries in Hungarian children. She performed these studies in collaboration with the Borrow Foundation, of which she was the Chairman-Trustee for 
many years. She registered with ORCA in 1976, and in 1987, as Co-President, she organized the ORCA Congress in Budapest. She later became an Honorary Member of ORCA.

The third field in her final active years dealt with the scientific evolution of dental education, the harmonization of dental education in Europe, and curricular changes within Central and Eastern European countries. On this topic, she contributed to numerous publications and also delivered lectures all over the world. She organized 5 national dental congresses with international participation, an ADEE Congress in 1990 and an FDI/ERO Congress in 1994 in Budapest, and she was the president of
ADEE in 1992 and 1993. She received an Honorary Membership of ADEE in 2005. She supervised $6 \mathrm{PhD}$ degrees. Her publications include more than 370 full papers, numerous abstracts, 2 monographs, and about 30 books/ book chapters in scientific and university teaching books. She delivered nearly 400 lectures all over the world.

Her outstanding work, international reputation, and charismatic personality impressed the Hungarian and the international dental research and education community. Her passing is a great loss for ORCA, as well as for the Hungarian and international dental community.

We treasure Professor Jolán Bánóczy in our hearts and memories. 